\title{
Does the learning space matter? An evaluation of active learning in a purpose-built technology-rich collaboration studio
}

\author{
Rebecca Donkin, Mary Kynn \\ School of Health and Sport Sciences, University of the Sunshine Coast, Queensland, Australia
}

\begin{abstract}
Studies in technology-rich learning environments have reported positive outcomes of active learning when compared to the traditional didactic classroom; others have found no benefits or have found interruption to learning due to the distraction of the technology. Evidence is required to support effective technology spaces that promote professional preparation, engagement and learning transfer. The impact of a technology-enabled collaboration studio on facilitating team-based learning for professional preparation through a case study in biomedical sciences was explored using a mixed method approach. Explicit assessment items as objective measures of student learning outcomes and implicit subjective, self-reported feelings of engagement and readiness for clinical practice is reported. Quantitative results showed an average $11.8 \%$ ( $p<0.001 ; 95 \%$ CI 6.6-17.0) improvement in the final examination score for those students who had content delivered in the collaborative environment compared to a standard classroom. Qualitative results also support the notion that engagement and learning was enhanced. Investment towards a technology-enabled collaboration studio has shown a contributory effect that improves final grade outcomes through increased engagement, communication, motivation and professionalism for the learner. This research informs guidelines for best practice in active learning environments, particularly in purpose-built high technology learning spaces.
\end{abstract}

Implications for practice or policy:

- Learning outcomes can be improved by investing in technology-enabled collaboration studios.

- Engagement and a sense of professional practice are enhanced by active learning in a technology-rich learning environment.

- Institutions should invest in technology-enabled active learning spaces.

Keywords: active learning, team-based learning, collaboration, technology, mixed method study

\section{Introduction}

In higher education, the broad term of active learning encompasses different learning and teaching methods that encourage activities that are interactive and engage the student to promote deep learning skills. Teambased learning (TBL; Michaelsen \& Sweet, 2011) is a method of active learning that requires learners to collaborate in a group, usually with additional resources such as online material. To engage students in learning, curriculum design in higher education has been successfully adapted to include a TBL format that accommodates multiple small-group learning opportunities in one large space (Dearnley et al., 2018). The learning theory is derived from the constructivist approach (Hrynchak \& Batty, 2012) and promotes active, student-centred learning using relevant problems whilst building teamwork skills. Learning is an active process in which meaning is developed on the basis of experience. In health science, TBL promotes equitable communication and contribution to learning while developing teamwork skills when students apply critical thinking by themselves with or without a facilitator to solve clinical problems (A. W. Burgess et al., 2012; González-Soltero et al., 2017). TBL has gained popularity in medical and health sciences education because of these benefits (A. Burgess et al., 2014; Haidet et al., 2012) and is critical to testing ideas and applying knowledge.

TBL is predominantly peer-led, and the academic's role is to facilitate learning through comments, questions and feedback. In this way, the students work through case-based clinical scenarios whilst being encouraged to collaborate. This empowers students to learn the necessary skills to work as a team member and to develop communication and critical learning skills (González-Soltero et al., 2017; Michaelsen \& Sweet, 2011; Parmelee et al., 2012). A pedagogical example of TBL is the model by Haidet et al. (2012), which includes the following guidelines for successful implementation of TBL: appropriate allocation of 
teams, allocation of directed study preparation before class, readiness assurance through assessment quizzes, immediate feedback online and in class, problem-solving through real-life clinical case studies, incentives to complete and continue learning activities and assessment of peer review through group case study presentations.

The increase in TBL, and the reduction in didactic passive teaching, has been shown to have a positive effect on active learning and academic achievement and reduce the need for large numbers of teaching staff (A. Burgess et al., 2014; A. W. Burgess et al., 2012; Norman, 2009). This is particularly true in clinical content delivery in biomedical science, which is achieved through the delivery of authentic problems, which can be demonstrated and solved in laboratory classes, with further exposure to the real clinical environment through work-integrated learning (Donkin \& Holmes, 2019).

However, it is not only the teaching delivery that may promote active learning and engage the student (Olasina, 2018) but also the physical learning space in which this happens, whether it is face-to-face, inclass or online (Thomas \& Thorpe, 2018). Research in this area is very limited; there is literature describing implementations and data outcome measures (Martinez-Maldonado et al., 2017) and how the structure of learning environments affects the behaviour of learners (Thompson et al., 2013), but there is minimal literature describing the student experience and comparing learning environments. There has been little research into the impact of the physical space in which we learn, particularly with regard to purpose-built technology-rich learning spaces (Brooks \& Solheim, 2014; Verdonck et al, 2018; Yeoman \& Wilson, 2019), which could further enrich active learning.

Technology-rich learning environments are somewhat novel, and their physical form is often variable, conditional to the institution implementing them. Minimum requirements include student access to hardware (computers, tablets, mobile devices) and software (Internet, learning management systems, elearning) in a purpose-built space with a flexible furniture arrangement that can accommodate small-group settings within a large class. Previous studies in technology-rich learning environments have reported positive outcomes of active learning when compared to the traditional didactic classroom (Park \& Choi, 2014); others have found no benefits (De Witte \& Rogge, 2014) or have found interruption to learning due to the distraction of the technology (White et al., 2014).

One reason purpose-built technology spaces are rare is because they require a large investment by the education sector and its staff. Not only is the cost of purchase a consideration but also the training and motivation for staff and students to use the technology. The teaching environment needs to prove its effectiveness compared to current practice and should be flexible for multiple disciplines and interprofessional learning if it is to be considered as an essential learning requirement.

There is a need for evidence that newly designed technology spaces are effective, have a positive impact on engagement, promote learning transfer and inform guidelines for best practice, particularly alongside TBL (River et al. 2016; Salter et al., 2013; Saqr et al,, 2018; Smith et al., 2013). As teaching and learning in a technologically advanced purpose-built collaboration studio is relatively new, there is no standard mechanism for evaluating the impact on student outcomes. Assessment and exams are useful evaluation tools for knowledge acquisition and are often tightly linked to explicit learning outcomes that are a valid measure of student performance (Figueroa-Cañas \& Sancho-Vinuesa, 2018). However, implicit skills around problem-solving, flexibility, communication, social interactions, time management and development of the "professional" are often not assessed or are disregarded. Interestingly, these are the skills and qualities that professional industry desires as graduate attributes (Michaelsen et al., 2008) and are also developed through TBL (Parmelee et al., 2012). Moreover, the physical space in which we learn these implicit skills and the ways we perceive how the "classroom" delivers implicit objectives can be overlooked.

The purpose of this research was to evaluate the impact of a technology-enabled collaboration studio on facilitating TBL using explicit assessment items as objective measures of student learning outcomes, and implicit subjective, self-reported feelings of engagement and readiness for clinical practice, using a case study in biomedical science. We hypothesised that a purpose-built technology-enabled collaboration studio would improve students' learning, measured by grade outcome and enhance students' engagement and motivation to learn, measured by self-assessment of learning. 


\section{Methods}

\section{Teaching space}

For the purpose of this study, teaching from 2015 to 2016 was conducted in a standard classroom, described in this study as a 20-person tutorial room with individual desktop computers arranged in forward-facing rows. The furniture and hardware were permanently secured and could not be rearranged for face-to-face group interaction. Teaching was didactic with a central lectern at the front of the class, and group interaction was limited due to individual desktop computers (no screen-sharing) and secured furniture configuration.

Teaching from 2017 to 2018 was conducted in a collaboration studio, a teaching space for up to 60 students with 10 group workstations, each for 3-6 people. The studio was designed to enhance both online and faceto-face learning simultaneously through a technology-rich environment to facilitate visual and interactive team-based learning activities. Each workstation had access to a desktop touchscreen computer, Wi-Fi for personal device use, Internet access and touchscreen technology linked to a multi-source ultra-wide enabled lectern screen. Students could work within and across teams using the central display monitor that projected onto the lectern screen, configured to a single display or as many as 10 displays to foster a collaborative approach to learning. All students could view and comment on the central display containing each team's activities (Figure 1).

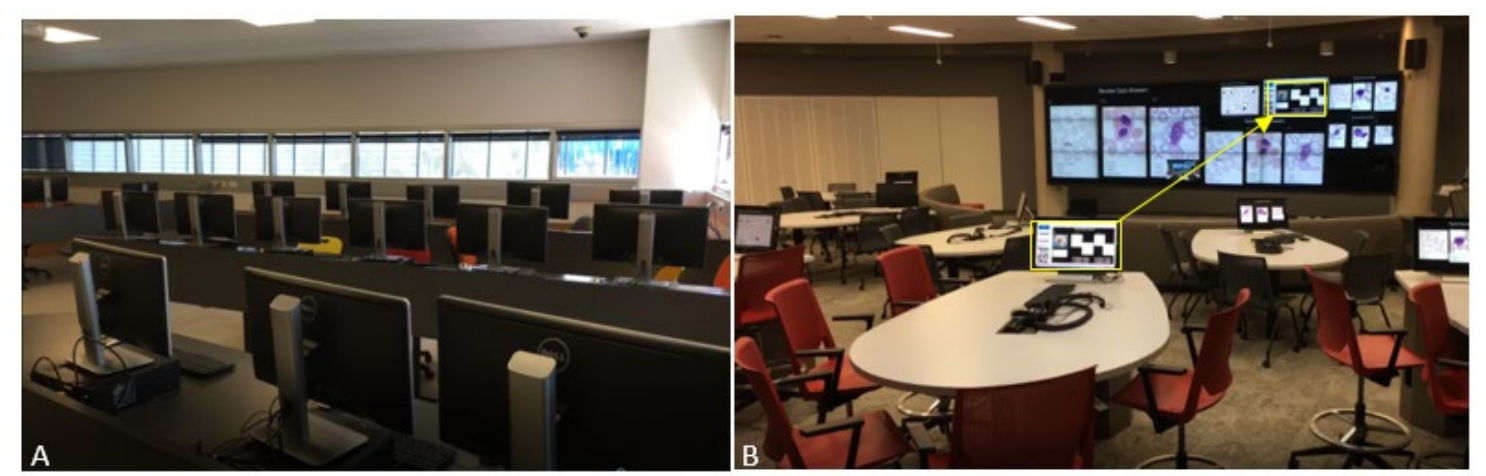

Figure 1. (A) Standard classroom: 20-person tutorial room with individual desktop computers; (B) Collaboration studio: 60-person room with multiple group workstations.

\section{Study design}

This was a mixed method study. Firstly, it evaluated student grade scores comparing learning outcomes between the standard teaching classroom and the collaboration studio. Secondly, a customised questionnaire, Student Evaluation of Team Based Learning in a Collaboration Studio, was used to evaluate student perceptions of TBL in a technology-rich collaboration studio after previously completing a subject in a standard teaching classroom. This questionnaire was administered to students in the collaboration studio to reflect on their learning in a standard classroom compared to learning in the collaboration studio. All students in the standard classroom and the collaboration studio were invited to complete learning feedback through the university evaluation survey after completion of the subject.

All participants $(N=105)$ were undergraduate students at a regional Australian university enrolled in a second-year haematology subject (study of blood disorders) in a biomedical science programme. All students had previously completed prerequisite first-year subjects in a standard teaching classroom. In their second-year haematology subject, students were enrolled in either the same standard teaching classroom $(n$ $=44)$ in 2015 to 2016 or the collaboration studio $(n=61)$ from 2017 to 2018 .

\section{Content of learning and summative assessment}

Students in either the standard teaching classroom or the collaboration studio received the same learning content. The learning curriculum was aligned to graduate attributes specifically designed for the programme and linked directly to assessment. The curriculum was designed to be learning-centred for students, standards-based for the profession, constructively aligned to assessment and career and future focused. The 
curriculum content comprised clinical case-based modules and e-learning lessons in haematology that had previously been peer reviewed and published (Donkin \& Askew, 2017). The same academic staff provided instruction in both the standard teaching classroom and the collaboration studio, and the assessment items (detailed below) remained the same. The curriculum for all students was based on a constructivist approach to learning that was active and student centred (Hrynchak \& Batty, 2012) and incorporated an adapted TBL model (Michaelsen \& Sweet, 2011). Specifically, students received directed study preparation before class (chapter textbook readings, lecture content and learning objectives), readiness assurance through formative assessment quizzes, immediate feedback online and in class (e-learning modules and simulated clinical case studies) and assessment of individual (case study examination) and peer review through group case study presentations.

The subject ran for 14 weeks in a semester and consisted of three summative assessments: (1) group oral presentation of an unknown haematology disorder, (2) individual practical case study examination and (3) individual multiple-choice and a short-answer clinical case study examination. Students also received formative feedback through quizzes, e-learning modules and simulated clinical case studies. Assessments were marked independently by the same two academic staff, and grades were ratified by a third independent moderator, regardless of teaching space or year the subject commenced. Assessors were not blind to the teaching space allocation as only one teaching space was offered each year the subject ran. Students were awarded a group mark for Assessment 1 and individual marks for Assessments 2 and 3 by the assessors. Students provided formative oral and written peer assessment for group work and were allocated individual marks $(5 \%)$ for participation in a question-and answer-forum for the group oral presentation. The final marks were calculated for each student and used as a measure of learning outcome.

All students had completed one or more undergraduate first-year subjects that utilised a standard classroom (20-person tutorial room with individual desktop computers) before enrolling in the second-year subject in either the standard classroom or the collaboration studio. After 9 weeks, students in the collaboration studio were invited to complete the Student Evaluation of Team Based Learning in a Collaboration Studio questionnaire to provide feedback through self-reflection of their learning experiences comparing a standard classroom to the collaboration studio. At completion of the subject (Week 14), all students enrolled in a standard classroom or collaboration studio were invited to provide feedback on their learning experience (haematology content, timing of feedback, assessment, teacher rating) through the university evaluation survey.

\section{Development of the student questionnaire}

We adapted the Student Evaluation of Team Based Learning in a Collaboration Studio questionnaire from a validated questionnaire designed by Thompson and colleagues (2009). The questionnaire was modified to evaluate student perceptions of TBL in a collaboration studio and reviewed by a panel of four higher education experts. The questionnaire consisted of a 39-item instrument that used a Likert scale to capture attitudes and experiences within the collaboration studio while students completed problem-based activities in a TBL format. The questionnaire covered five themes: student experience of collaborating in a team environment; motivation to learn; importance of knowledge acquisition; inhibition of motivation to learn; and student perception of peer knowledge, communication and teamwork skills. Closed questions were answered on a simple three-level Likert scale (agree, disagree, or unsure), and an option for "other" openended responses was also provided. The questionnaire was paper-based with no incentive to promote participation; however; it was administered when students were required to attend a face-to-face learning assessment session. We were not present when the questionnaire was administered. An independent academic collated the anonymous questionnaires. Ethics approval was obtained from the University of the Sunshine Coast Human Research Ethics Committee, A/17/934 \& A/18/1053, and informed consent for participation was obtained from the student participants.

\section{Data analysis}

Quantitative data and frequency analytics were analysed using SPSS version 25. Main outcomes were approximately normally distributed with homogenous variances and compared with independent sample $t$ tests. Chi-squared tests of independence were used for cohort comparisons. Qualitative respondent answers were analysed to identify a theme or keyword that was then used in a coding scheme (Graneheim \& 
Lundman, 2004). We independently coded each comment for a major theme. The interrater agreement was assessed with Cohen's kappa, and discrepancies were discussed and resolved for final analysis.

To adequately detect a $10 \%$ difference in grade outcomes between student learning in a standard teaching space and that in the collaboration studio with statistical power $80 \%$, alpha $=0.05$ and assuming a standard deviation of 12 points, a sample size of at least 23 students per group was required (Brant, 2016).

\section{Results}

All second-year undergraduate students (105) consented to participate in the study. There were 44 students enrolled in the standard teaching classroom and 61 students in the collaboration studio. The students were predominantly female and over the age of 20 , with slightly more males enrolled in the collaboration studio; however, these differences were not statistically significant (Table 1).

To exclude any bias between students enrolled in either of the two learning environments, grade point averages were calculated from the first-year foundation subject before commencing second year. The average mark for students who enrolled in the standard teaching classroom was $74 \%(\mathrm{SD} \pm 12$ ), and the average mark for students enrolled in the collaboration studio was $77 \%(\mathrm{SD} \pm 10)$, this was not statistically different $(p=0.184)$.

Table 1

Demographic characteristics

\begin{tabular}{llll}
\hline & $\begin{array}{l}\text { Standard teaching classroom } \\
n(\%)\end{array}$ & $\begin{array}{l}\text { Collaboration studio } \\
n(\%)\end{array}$ & Sig. \\
\hline Gender & & $43(70.5)$ & 0.311 \\
Female & $35(79.5)$ & $18(29.5)$ & \\
Male & $9(20.5)$ & & 0.788 \\
Age & & $24(39)$ & \\
$<20$ & $16(36)$ & $37(61)$ & 105 \\
$>20$ & $28(64)$ & $61(100)$ & \\
\hline Total & $44(100)$ & & \\
\hline
\end{tabular}

\section{Quantitative assessment}

Overall, students in the collaboration studio scored on average 5.2\% higher than students in the standard classroom $(p=0.012 ; 95 \%$ confidence interval for the difference 1.1-9.3). However, there was some variation across individual tasks. The first task was the group presentation, and students in the collaboration studio performed worse on average by $6.3 \%$ ( $p=0.017$; $95 \%$ confidence interval for the difference $1.1-$ 11.4); this is explored further in the Discussion future directions and limitations section. Although students in the collaboration studio achieved higher scores in Task 2 (individual practical case study examination), there was no statistical difference. However, there was a statistical difference for students in the collaboration studio performing on average $11.8 \%$ higher on the final examination $(p<0.001 ; 95 \%$ confidence interval for the difference 6.6-17.0). Results by task and total grade are presented in Figure 2. 


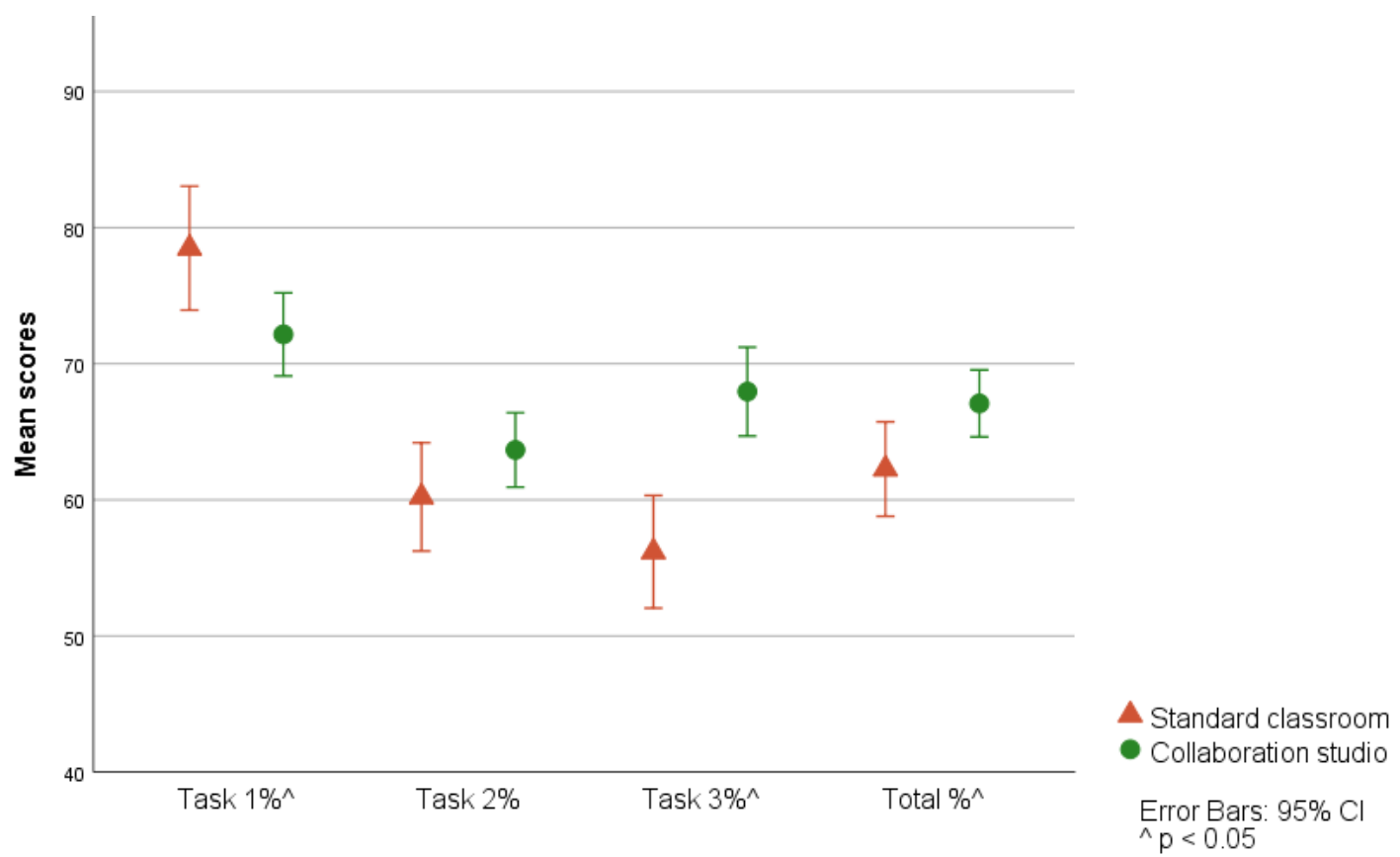

Figure 2. Results presented by task assessment and total grade in a standard teaching classroom (2016 to 2017) versus the collaboration studio (2017 to 2018)

\section{Student questionnaire responses}

All participants $(61 ; 100 \%)$ in the collaboration studio voluntarily completed the paper-based closed item Student Evaluation of Team Based Learning in a Collaboration Studio questionnaire regarding their experience in the collaboration studio and TBL. For most students (77\%), it was their first time enrolled in a subject that was taught in the collaboration studio; some students $(23 \%)$ had previous exposure through enrolment in an elective subject. All students (100\%) had previously completed prerequisite first-year subjects in standard teaching classrooms for comparison. The majority of students (97\%) responded that they participated in TBL and the blended learning activities in the collaboration studio and received appropriate feedback. The motivation to learn was highest in the themes of improving knowledge (100\%), high-quality teaching (93\%) and application to the workforce (92\%). Approximately two thirds of students $(63 \%)$ stated that working as a team and the flexibility and convenience of online learning motivated them to learn, while $78 \%$ of students responded the use of modern technology was a motivator to learn. Motivation to learn was linked directly to what they perceived was the practical value of the knowledge. Almost all students (98\%) believed what they had learnt would be relevant in the future, and $95 \%$ believed it would also prepare them for the clinical workforce. Outside commitments was the greatest reason students gave as an explanation as to why their learning was inhibited, with $57 \%$ of students citing family, current work or social commitments inhibiting learning outcomes. Approximately $3 \%$ of students responded that the technology would inhibit learning, and $12 \%$ stated that working in a group would be inhibitory to learning. Students overwhelmingly reported that they believed their peers in their team were knowledgeable (98\%), enthusiastic to learn (93\%), reliable (92\%) and well prepared $(90 \%)$. A complete list of the qualitative closed item student questionnaire is reported in Figure 3. 


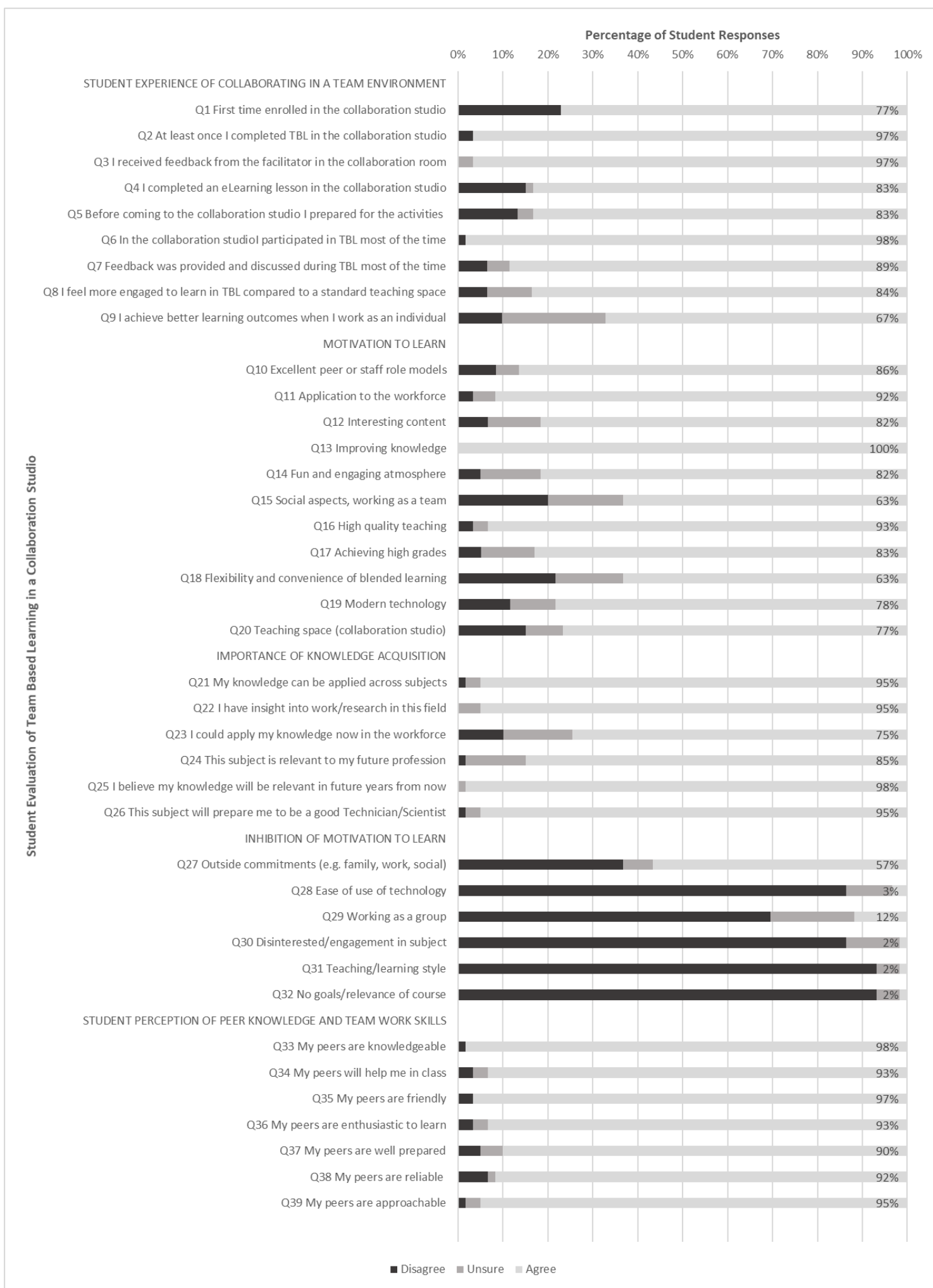

Figure 3. Student Evaluation of Team Based Learning in a Collaboration Studio questionnaire and student results reported by percentage

\section{Student experience of the collaboration studio}

Two thirds (40 out of 61) of the participants completed the open-ended questionnaire and provided comments about their perception of the collaboration studio in comparison with a standard classroom for 
learning. Respondent answers were analysed to identify a theme or keyword that was used in a coding scheme (Graneheim \& Lundman, 2004). Most comments were a single sentence or sentence fragment, and five key themes were identified: use of technology, group work experience, professional experience, room environment and teacher preference. The interrater agreement was moderate $($ Cohen's kappa $=0.75)$ and discrepancies were resolved by discussion.

Theme 1: Use of technology in the collaboration studio

Most of the comments referred to the technology positively in the collaboration studio with $30 \%$ of students responding that the technology in the room was useful and enjoyable for the learner. Typical responses included, "access to a central shared PC has helped with material" and "having the technology allowed for easier viewing of [virtual] blood films" and "compared to a regular classroom the technology environment is more equipped for learning". A small percentage of respondents $(7.5 \%)$ felt the technology created problems or wasted time, for example, "the technology can be confusing, and time was wasted trying to figure out the technology".

Theme 2: Group work experience in the collaboration studio

Almost a quarter of the respondents $(22.5 \%)$ felt the collaboration studio was good for group work and/or improved the group work experience:

Collaboration studio provides a more interactive learning style that makes it easier to learn individually and within a group.

More informative being able to work in small groups and answer questions together on the computer at the desk, it doesn't isolate anyone.

Definitely prefered working in groups for the collaboration studio than in a regular class, more interactive.

Learning [in the collaboration studio] helped us learn in a group and engage with the class in constructive conversations.

However, 7.5\% commented that they did not like group work irrespective of context: "on assessment I prefer to work alone".

Theme 3: Professional experience

A total of $15 \%$ of students commented that the collaboration studio felt professional or like work experience and that they had professional role models applying a team approach to learning:

Feels more professional [compared to standard classroom], we had a different type of learning as it is applying technology for work related scenarios.

We had a positive interaction with real life examples, like in the profession.

Theme 4: Room environment

The environment of the room was described by students $(11.5 \%)$ in the physical context and the feelings the room evoked. Students commented on the room temperature, space, size and furniture choice:

I can actually see the board.

Bigger collaboration room made it easier to concentrate.

Stools and standing [in the collaboration room] engages more, sitting is more class like formal.

Students' emotional comments included:

I would like to spend more time in the colaboraton room, it is more exciting and increases motivation.

It's a good, new \& exciting experience for learning, it would be good to see more of these rooms across campus.

Allows for more peer/teacher feedback.

Theme 5: Teacher preference

The remaining comments $(6 \%)$ included remarks about liking the teaching staff in the collaboration studio: 
I think teaching staff are excellent.

I had more attention from tutors [in the collaboration studio] it helped me develop new knowledge.

The tutor confirms student understanding regularly throughout the class.

\section{Student experience of the subject}

In total, 15 out of $44(34 \%)$ of participants in the standard teaching classroom and 17 out of $61(28 \%)$ of participants in the collaboration studio provided general feedback about the subject through the university evaluation survey. Due to the low response rate and statistical validity, general feedback on the subject is not reported in this paper.

\section{Discussion, future directions and limitations}

This study evaluated the impact of a technology-enabled collaboration studio on facilitating TBL using a mixed method approach of quantitative and qualitative data through assessment and a customised questionnaire. The study is unique as it captured both explicit assessment items as objective measures of student learning outcomes, and implicit subjective, self-reported feelings of engagement and readiness for clinical practice, using a case study in biomedical science.

While it was anticipated that a TBL model would benefit explicit student outcomes, it was an unanticipated finding that the implicit outcomes of engagement and a sense of professionalism positively developed in the collaboration studio. Learning tools that provide an interactive team environment, whether that is online or face-to-face, may provide better access to learning material, but this raises the question: does the learning space really matter?

\section{Purpose-built collaborative learning space}

There is a growing interest in technology-built learning spaces in higher education to provide a platform to encourage TBL and learning through collaboration (Van Horne et al., 2014). Previous studies have focused on the use of technologies (Ellis, 2016) and explicit student outcomes (Brooks \& Solheim, 2014), albeit few have reported the student experience and behaviour in a collaborative environment (Brooks, 2012; Verdonck et al., 2018). Investment in creating learning spaces with technology-rich facilities is high, and evaluation of these learning spaces is critical if approaches to learning and teaching are focused on active learning (Cleveland \& Fisher, 2014).

In this study, learning occurred simultaneously in a physical and virtual space in real time in a collaborative face-to-face or online environment. This enabled students to actively participate in TBL in small groups (3-6 people) and discuss real patient case scenarios using simulated pathology techniques, virtual slides and e-learning modules (Donkin \& Askew, 2017). Results from our study suggest the learning space can impact engagement, with the majority of students (77\%) responding that the collaboration studio motivated them to learn. The collaboration studio provided activities with an incentive structure to maximize student collaboration and improve grades both overall and for individual assessment items. The purpose-built collaborative space shifted the notion of learning transfer from didactic teaching to peer collaboration. The designed collaborative space of multiple desks in one large room promoted positive interdependence between and within teams, which was reported in the student questionnaire survey. The combination of digital technology and appropriate space supported simultaneous online and face-to-face learning both within and across teams. This configuration afforded easily accessible sharing of knowledge through a multi-source enabled lectern screen linked to the group workstations, which promoted peer engagement and reflection. Learning was dependent on cognitive co-construction, shared knowledge and reduced cognitive load, which, overall, improves self-efficacy and performance (Tolsgaard et al., 2016). Results from this study suggest future directions in active learning should be designed with the learning space in mind and in consideration of how the perceived environment can improve cognitive and non-cognitive learning. 


\section{Student experience of professionalism}

An incidental finding from this study was the development of the professional learner. It is known that collaborative or team-based learning improves communication skills (Zgheib et al., 2016), but it appears that studying collegially on real-life clinical case studies also has benefits in developing graduate attributes in the biomedical science profession. Students in this study commented that working in the collaboration studio "felt more professional" and provided "professional role modelling". Having a safe environment to discuss a virtual patient in a team and work through a clinical case develop skills in communication, professional enquiry, critical thinking and motivation without the potential stress and cognitive demands of working with a real patient in a clinical setting (Hege et al., 2018). It is plausible that the "space" in which we learn significantly affects our emotional and engaging responses (Kayumova \& Tippins, 2016) and shifts the notion of learning from the concept of student to future graduate.

\section{Teamwork}

As discussed by Haidet et al. (2012), one of the core designs of TBL is team formation with equal allocation of resources (including student attributes). However, students rarely allocate themselves across groups and diversify their team if allowed to self-select (Farland et al., 2013). In practice, as a graduate in a working profession, allocation of a team is rarely by choice, and the necessary skills to work in a group need to be developed and acquired. Therefore, undergraduate students should be exposed to peers with different backgrounds and experiences to develop their team and communication skills and prepare them for their future professional organisation.

In this study, there were differences in Task 1 team selection (NB. content was identical). In a standard teaching classroom, there are challenges to working within a team due to the physical nature of the room (didactic layout) and the fixed furniture arrangement. As a consequence, students self-selected their teams with friends and who they liked to sit with in a didactic layout for Task 1. Social constructs, such as being friends or having a familiar or similar interest, influenced team selection. Developing the social skills of working together was likely more rapid for students in the standard teaching classroom compared to student teams in the collaboration studio who were purposefully chosen by the instructor.

In the collaboration studio, the instructor allocated students to a team for the entire semester. Purposeful allocation with the intent to evenly distribute students based on gender (females to males), age (mature or school leaver) and academic distribution (grade point average) was considered, so that no individual group had more weighting in group dynamic than another. The majority of the students in the collaboration studio believed the peers in their group were knowledgeable (98\%) and enthusiastic to learn (93\%). However, there was a small percentage who were unsure or believed their peers were neither reliable $(8 \%)$ nor approachable (5\%). Student comments that reflected this included: "the collaborative classroom was wonderful, the assignment of the group was not" and "I didn't like the fact that I was placed in a group and I couldn't choose who I wanted to work with". Early assessment of instructor-selected teams may impact negatively on students' scores if teamwork and communication skills have not had time to develop or resistance to participation or poor motivation to learn influence the group dynamic (Lai, Lin, \& Yueh, 2018). Peer versus instructor team selection is the probable contributing variable that influenced performance in Task 1 for students in the collaboration studio, not necessarily the learning space itself. This research emphasises that when instructors implement team formation, it is imperative to communicate to students the reasons they were assigned to a team, the pedagogical evidence of TBL and the importance of promoting a positive and inclusive team atmosphere.

\section{Limitations}

Research suggests that at least 40 hours of teamwork are required to promote team formation, productivity and peer learning (Farland et al., 2013; Michaelsen et al., 2008). In our study, teamwork was required to learn and use the technology in the collaboration studio along with developing team and social skills to constructively work together. A limitation of this study is the time students had in-class to develop team skills before Task 1 was assessed (10 hours), which may have impacted their learning and was reflected in grade outcomes. However, after working together for more than 10 hours, learning significantly improved, evident from improved grades. We believe the collaborative learning space affords better social constructs; however, social constructs take time to develop. This is likely why there is improvement with grades with 
time ( $>10$ hours) as the use of space, technology and social constructs are able to fully develop. This does not appear to occur in a standard classroom. Students' grades do not improve in a standard classroom even though they have the same technology and learning content as students in the collaboration studio. The space in which we learn does appear to matter.

A small number of students $(n=14)$ had previous exposure to learning in the collaborative studio, and this may have influenced their perception of the learning space and motivation to learn. Perhaps, the professional atmosphere of learning in a room called the collaboration studio could have influenced learning behaviours and the ideology of professional practice. However, it is important to report that not all students liked being in the collaboration studio and working in a team environment; and this may influence engagement in the subject and student outcomes. Most students responded that the social aspects of working in a team $(63 \%)$ and modern technology $(78 \%)$ provided a positive experience, whereas for a minority of students, this was a negative experience. Although benefits of group work include longer student retention of information and meaningful learning outcomes (Fung \& Howe, 2012; Joo \& Dennen, 2017), there is a small proportion of students for whom there are adverse learning outcomes due to poor effort and little contribution as well as a preference for individual learning (Piezon \& Ferree, 2008). Poor effort and contribution may be linked to motivation to learn, with $57 \%$ of students in the study citing family, work or social commitments that may inhibit their learning throughout the semester.

The merging of technology and the environment may have influenced the outcomes from the collaboration studio. If it were possible to separate the technology from the furnishings, it might be possible to investigate how each contributed to the results. This may be an opportunity to explore in future research. However, the whole may be more than the sum of the parts, and disentangling contributing factors may not be so simple. A previous study examined one aspect of the technology (e-learning module) versus in-class lessons (Donkin \& Askew, 2017). The study reported an increase in mean summative assessment scores and final grade for students who completed the e-learning module. For the cohort, interactive e-learning modules (technology) improved grade outcomes compared to an in-class didactic lesson. However, the result was dependent on motivation and engagement of the student to voluntarily participate and use the technology. One could argue that highly motivated and engaged students would likely succeed in any environment whether it involved technology, different furnishings or a collaborative environment.

In the current study, it was important to report the student experience, so they could provide insight into their experience with the technology - whether that be in the collaboration studio or a traditional classroom - as the learning content and assessment were identical. It would have been interesting if the response rate from the standard classroom students was higher to report findings from a control cohort. Due to the low response rate and statistical validity, general feedback on the subject from the standard classroom was not reported in this paper. Instead, inference of student perception comparing a standard classroom experience to the collaboration studio was reported.

\section{Conclusions and implications}

In summary, the results from this study suggest that the physical space in which we learn does have an effect on learning. A technology-rich collaborative space can improve explicit learning outcomes through student assessment grades but also assists with the development of implicit outcomes such as engagement, communication, motivation and professionalism.

The reasonable conclusion of this research is that the learning space does matter especially when learning is informed by best practice in active learning (purposeful team formation, adequate instruction for use of technology and a constructivist approach to teaching through TBL). Small-group and task-focused activities of TBL provide student-centred learning; however; additional support through a technology-enabled learning space encourages further group facilitation and a sense of professional relevance. A purpose-built technology-enabled collaborative environment can promote motivation to learn and improve grade outcomes compared to a traditional standard classroom. This research informs guidelines for best practice in these spaces using a valid and reliable instrument for future research to assess and evaluate active learning in purpose-built technology-rich learning spaces. Particularly, the questionnaire evaluates implicit student outcomes in how the learning space enriches TBL and the benefits of investment in a technologyenabled collaboration studio. Although this instrument was specific for the collaboration studio and applied 
to a biomedical science programme, further research is needed to assess if this approach and the use of a collaborative studio are effective in other subjects and disciplines.

\section{Acknowledgements}

The authors would like to thank the academic and educational designers for assisting with the teaching, online tools and collaborative design of this study. Specifically, the authors thank Mrs Elizabeth Askew (elearning module developer); Associate Professor Lin Fung (subject coordinator and lecturer); Mr Geoff Simon (lecturer); and Ms Carola Hobohm and Ms Theresa Ashford (educational technology functional analysts). The authors also thank Professor Richard Burns for support with academic communication and the students who participated in the study.

\section{References}

Brant, R. (2016). Inference for means: Comparing two independent samples. The University of British Columbia. https://www.stat.ubc.ca/ rollin/stats/ssize/n2.html

Brooks, D. C. (2012). Space and consequences: The impact of different formal learning spaces on instructor and student behavior. Journal of Learning Spaces, 1(2). https://libjournal.uncg.edu/jls/article/view/285

Brooks, D. C., \& Solheim, C. A. (2014). Pedagogy matters, too: The impact of adapting teaching approaches to formal learning environments on student learning. New Directions for Teaching and Learning, 2014(137), 53-61. https://doi.org/10.1002/t1.20085

Burgess, A., McGregor, D., \& Mellis, C. (2014). Medical students as peer tutors: a systematic review. BMC Medical Education, 14(1), Article 115. https://doi.org/10.1186/1472-6920-14-115

Burgess, A. W., Ramsey-Stewart, G., May, J., \& Mellis, C. (2012). Team-based learning methods in teaching topographical anatomy by dissection. ANZ Journal of Surgery, 82(6), 457-460. https://doi.org/10.1111/j.1445-2197.2012.06077.x

Cleveland, B., \& Fisher, K. (2014). The evaluation of physical learning environments: A critical review of the literature. Learning Environments Research, 17(1), 1-28. https://doi.org/10.1007/s10984-0139149-3

De Witte, K., \& Rogge, N. (2014). Does ICT matter for effectiveness and efficiency in mathematics education? Computers \& Education, 75, 173-184. https://doi.org/10.1016/j.compedu.2014.02.012

Dearnley, C., Rhodes, C., Roberts, P., Williams, P., \& Prenton, S. (2018). Team based learning in nursing and midwifery higher education a systematic review of the evidence for change. Nurse Education Today, 60, 75-83. https://doi.org/10.1016/j.nedt.2017.09.012

Donkin, R., \& Askew, E. (2017). An evaluation of formative "in-class" versus "e-learning" activities to benefit student learning outcomes in biomedical sciences. Journal of Biomedical Education, 2017. https://doi.org/10.1155/2017/9127978

Donkin, R., \& Holmes, M. (2019). Bridging the gap between Australian pathology and university education: Student perceptions of a career pathway in medical laboratory science. International Journal of Work-Integrated Learning, 20, 1-14. https://www.ijwil.org/files/IJWIL_20_1_1_14.pdf

Ellis, R. A. (2016). Qualitatively different university student experiences of inquiry: Associations among approaches to inquiry, technologies and perceptions of the learning environment. Active Learning in Higher Education, 17(1), 13-23. https://doi.org/10.1177/1469787415616721

Farland, M., Sicat, B., Franks, A., Pater, K. S., Medina, M. S., \& Persky, A. (2013). Best practices for implementing team-based learning in pharmacy education. American Journal of Pharmaceutical Education, 77(8). https://doi.org/10.5688/ajpe778177

Figueroa-Cañas, J., \& Sancho-Vinuesa, T. (2018). Investigating the relationship between optional quizzes and final exam performance in a fully asynchronous online calculus module. Interactive Learning Environments, 1-11. https://doi.org/10.1080/10494820.2018.1559864

Fung, D., \& Howe, C. (2012). Liberal studies in Hong Kong: A new perspective on critical thinking through group work. Thinking Skills and Creativity, 7(2), 101-111. https://doi.org/10.1016/j.tsc.2012.04.002

González-Soltero, R., Learte, A. I. R., Sánchez, A. M., \& Gal, B. (2017). Work station learning activities: A flexible and scalable instrument for integrating across basic subjects in biomedical education. $B M C$ Medical Education, 17(1), Article 236. https://doi.org/10.1186/s12909-017-1084-z 
Graneheim, U. H., \& Lundman, B. (2004). Qualitative content analysis in nursing research: concepts, procedures and measures to achieve trustworthiness. Nurse Education Today, 24(2), 105-112. https://doi.org/10.1016/j.nedt.2003.10.001

Haidet, P., Levine, R., Parmelee, D., Crow, S., Kennedy, F., Kelly, P. A., Richards, B. F. (2012). Perspective: guidelines for reporting team-based learning activities in the medical and health sciences education literature. Academic Medicine, 87(3), 292-299. https://doi.org/10.1097/ACM.0b013e318244759e

Hege, I., Kononowicz, A. A., Kiesewetter, J., Foster-Johnson, L., \& Kestler, H. A. (2018). Uncovering the relation between clinical reasoning and diagnostic accuracy - An analysis of learner's clinical reasoning processes in virtual patients. PLOS ONE, 13(10). https://doi.org/10.1371/journal.pone.0204900

Hrynchak, P., \& Batty, H. (2012). The educational theory basis of team-based learning. Medical Teacher, 34(10), 796-801. https://doi.org/10.3109/0142159X.2012.687120

Joo, M.-H., \& Dennen, V. P. (2017). Measuring university students' group work contribution: scale development and validation. Small Group Research, 48(3), 288-310. https://doi.org/10.1177/1046496416685159

Kayumova, S., \& Tippins, D. (2016). Toward re-thinking science education in terms of affective practices: Reflections from the field. Cultural Studies of Science Education, 11(3), 567-575. https://doi.org/10.1007/s11422-015-9695-3

Lai, T.-L., Lin, F. T., \& Yueh, H.-P. (2018). The effectiveness of team-based flipped learning on a vocational high school economics classroom. Interactive Learning Environments, 28(1), 130-141. https://doi.org/10.1080/10494820.2018.1528284

Martinez-Maldonado, R., Goodyear, P., Carvalho, L., Thompson, K., Hernandez-Leo, D., Dimitriadis, Y., Prieto, L. P., \& Wardak, D. (2017). Supporting collaborative design activity in a multi-user digital design ecology. Computers in Human Behavior, 71, 327-342. https://doi.org/10.1016/j.chb.2017.01.055

Michaelsen, L. K., Parmelee, D. X., McMahon, K. K., \& Levine, R. E. (2008). Team-based learning for health professions education: A guide to using small groups for improving learning. Stylus Publishing.Michaelsen, L. K., \& Sweet, M. (2011). Team-based learning. New Directions for Teaching and Learning, 2011(128), 41-51. https://doi.org/10.1002/tl.467

Norman, G. (2009). Teaching basic science to optimize transfer. Medical Teacher, 31(9), 807-811. https://doi.org/10.1080/01421590903049814

Olasina, G. (2018). Human and social factors affecting the decision of students to accept e-learning. Interactive Learning Environments, 27(3), 363-376. https://doi.org/10.1080/10494820.2018.1474233

Park, E. L., \& Choi, B. K. (2014). Transformation of classroom spaces: Traditional versus active learning classroom in colleges. Higher Education: The International Journal of Higher Education and Educational Planning, 68(5), 749-771. https://doi.org/10.1007/s10734-014-9742-0

Parmelee, D., Michaelsen, L. K., Cook, S., \& Hudes, P. D. (2012). Team-based learning: A practical guide: AMEE Guide No. 65. Medical Teacher, 34(5), 275-287. https://doi.org/10.3109/0142159X.2012.651179

Piezon, S. L., \& Ferree, W. D. (2008). Perceptions of social loafing in online learning groups: A study of public university and U.S. Naval War College students. International Review of Research in Open and Distance Learning, 9(2), 1-17. https://doi.org/10.19173/irrodl.v9i2.484

River, J., Currie, J., Crawford, T., Betihavas, V., \& Randall, S. (2016). A systematic review examining the effectiveness of blending technology with team-based learning. Nurse Education Today, 45, 185192. https://doi.org/10.1016/j.nedt.2016.08.012

Salter, D., Thomson, D. L., Fox, B., \& Lam, J. (2013). Use and evaluation of a technology-rich experimental collaborative classroom. Higher Education Research \& Development, 32(5), 1-15. https://doi.org/10.1080/07294360.2013.777033

Saqr, M., Fors, U., \& Tedre, M. (2018). How the study of online collaborative learning can guide teachers and predict students performance in a medical course. BMC Medical Education, 18(1), Article 24. https://doi.org/10.1186/s12909-018-1126-1

Smith, M. K., Jones, F. H. M., Gilbert, S. L., \& Wieman, C. E. (2013). The classroom observation protocol for undergraduate stem (COPUS): A new instrument to characterize university STEM classroom practices. CBE Life Sciences Education, 12(4), 618-627. https://doi.org/10.1187/cbe.13-08$\underline{0154}$ 
Thomas, G., \& Thorpe, S. (2018). Enhancing the facilitation of online groups in higher education: A review of the literature on face-to-face and online group-facilitation. Interactive Learning Environments, 27(1), 62-71. https://doi.org/10.1080/10494820.2018.1451897

Tolsgaard, M. G., Kulasegaram, K. M., \& Ringsted, C. V. (2016). Collaborative learning of clinical skills in health professions education: The why, how, when and for whom. Medical Education, 50(1), 6978. https://doi.org/10.1111/medu.12814

Thompson, B. M., Levine, R. E., Kennedy, F., Naik, A.D., Foldes, C. A., Coverdale, J. H., Kelly, P. A., Parmelee, D., Richards, B. F., Haidet, P. (2009). Evaluating the quality of learning-team processes in medical education: development and validation of a new measure. Academic Medicine, 84(10), S124S127. https://doi.org/10.1097/ACM.0b013e3181b38b7a

Thompson, K., Ashe, D., Carvalho, L., Goodyear, P., Kelly, N., \& Parisio, M. (2013). Processing and Visualizing Data in Complex Learning Environments. American Behavioral Scientist, 57(10), 14011420. https://doi.org/10.1177/0002764213479368

Van Horne, S., Murniati, C. T., Saichaie, K., Jesse, M., Florman, J. C., \& Ingram, B. F. (2014). Using qualitative research to assess teaching and learning in technology-infused TILE classrooms. New Directions for Teaching and Learning, 2014(137), 17-26. https://doi.org/10.1002/tl.20082

Verdonck, M., Greenaway, R., Kennedy-Behr, A., \& Askew, E. (2018). Student experiences of learning in a technology-enabled learning space. Innovations in Education and Teaching International, 56(3), 270-281. https://doi.org/10.1080/14703297.2018.1515645

White, C., Bradley, E., Martindale, J., Roy, P., Patel, K., Yoon, M., \& Worden, M. K. (2014). Why are medical students 'checking out' of active learning in a new curriculum? Medical Eeducation, 48(3), 315-324. https://doi.org/10.1111/medu.12356

Yeoman, P., \& Wilson, S. (2019). Designing for situated learning: understanding the relations between material properties, designed form, and emergent learning activity. British Journal of Educational Technology, 50(5), 2090-2108. https://doi.org/10.1111/bjet.12856

Zgheib, N. K., Dimassi, Z., Bou Akl, I., Badr, K. F., \& Sabra, R. (2016). The long-term impact of teambased learning on medical students' team performance scores and on their peer evaluation scores. Medical Teacher, 38(10), 1017-1024. https://doi.org/10.3109/0142159X.2016.1147537

Corresponding author: Rebecca Donkin, rdonkin@usc.edu.au

Copyright: Articles published in the Australasian Journal of Educational Technology (AJET) are available under Creative Commons Attribution Non-Commercial No Derivatives Licence (CC BY-NC-ND 4.0). Authors retain copyright in their work and grant AJET right of first publication under CC BY-NC-ND 4.0.

Please cite as: Donkin. R., \& Kynn, M. (2021). Does the learning space matter? An evaluation of active learning in a purpose-built technology-rich collaboration studio. Australasian Journal of Educational Technology, 37(1), 133-146. https://doi.org/10.14742/ajet.5872 